\title{
Bonding bare die LEDs on PET foils for lighting applications: thermal design modeling and bonding experiments
}

\author{
D.A. van den Ende $^{1}$, R.H.L. Kusters ${ }^{1}$, M. Cauwe ${ }^{2}$, A. van der Waal ${ }^{3}$ and J. van den Brand ${ }^{1}$ \\ ${ }^{1}$ Holst Centre/TNO, HTC31, P.O. box 8550, 5605 KN Eindhoven, the Netherlands \\ 2 Imec Cmst, Technologiepark Zwijnaarde, Grote Steenweg Noord, B-9052 Zwijnaarde, Belgium \\ ${ }^{3}$ TNO, Materials for Integrated Products, De Rondom 1, 5612AP, Eindhoven, the Netherlands \\ daan.vandenende@tno.nl
}

\begin{abstract}
Integration of LEDs on flexible foil substrates is of interest for flexible lighting applications and flexible photonic devices. A matrix of LEDs on a foil combined with a diffuser can be a potential alternative for flexible OLED lighting devices. Preferably, these LEDs are integrated in an unpackaged, bare die form as it reduces cost, footprint and thickness. As a substrate, preferably low cost materials like polyesters (PET) are being used, especially for large area devices. However, the use of these materials imposes some limitations. Most notably, the low temperature stability $\left(<100^{\circ} \mathrm{C}\right.$ continuous use temperature $)$ of these materials limits the maximum temperatures during the manufacturing process and poses constraints on the thermal design of the device. The current paper describes the results of research on possibilities for integrating bare die LEDs with low cost flexible PET foils. Finite element (FE) thermal modeling has been performed of possible designs of adhesively bonded LED-on-foil and laminated LED-in-foil configurations. The role of the different materials and the effect of their geometries on the temperature distribution in the simulated devices are discussed. The results give insight in measures that can be taken to keep the temperature of all the components of the device within operational limits. For LEDs bonded on $\mathrm{Cu}$ PET foil the modeled temperature distributions are compared to experimentally observed temperature distributions in LED on PET foil reference devices using infrared thermal imaging. Besides this, initial studies on directly bonding LEDs on etched $\mathrm{Cu}$ on PET substrates using anisotropic conducting adhesives and isotropic conducting adhesives were performed. An experimental comparison is made between the different techniques based on temperature/humidity reliability and flexural stability of the bonded LEDs, based on these preliminary results.
\end{abstract}

\section{Introduction}

Systems-in-foil (SIF) is a class of electronics in which a full system is integrated into a flexible end product [1]. Due to continuously decreasing LED chip prices [2], integration of bare die LEDs on foil is becoming of interest for low cost and flexible lighting applications. Packaged LEDs have been demonstrated on flexible polyimide (PI) foils for automotive applications [3]. However, packaged LEDs are relatively expensive and the package relatively thick compared to the LED die. Hence, the use of bare die LEDs can reduce the cost of the foil based system and also increase its flexibility.

Also, PI foils are too expensive for large scale applications. By using cost effective polyesters such as PET (polyethylene teraphtalate), the substrate costs can be reduced by up to a factor 10 [4]. However, PET has a much lower thermal stability than PI [5]. This poses limitations for the integration technologies that can be used for manufacturing the foils $[5,6]$. The foil system must be designed to avoid hot spots, which can affect the reliability of the PET foil. Moreover, the efficiency and lifetime of LEDs suffer significantly with increasing junction temperature. Therefore, it is imperative that the design copes well with the heat that is generated by the LEDs during operation [3].

In this paper results of thermal modeling and experiments are described for best design of substrate. Also a first exploration has been performed on the possibilities for bonding of bare die LEDs on PET foils.

\section{Modelling}

The dimensions of the system is presented in Figure 1. It consists of a bare die LED which is flip chip surface mounted on a PET foil having $\mathrm{Cu}$ circuitry. The given dimensions are used in the thermal simulations of the system-in-foil. The total width of the repeating unit (i.e. corresponding to lateral spacing of the LEDs in an array) was one of the parameters that were varied during the simulation study.

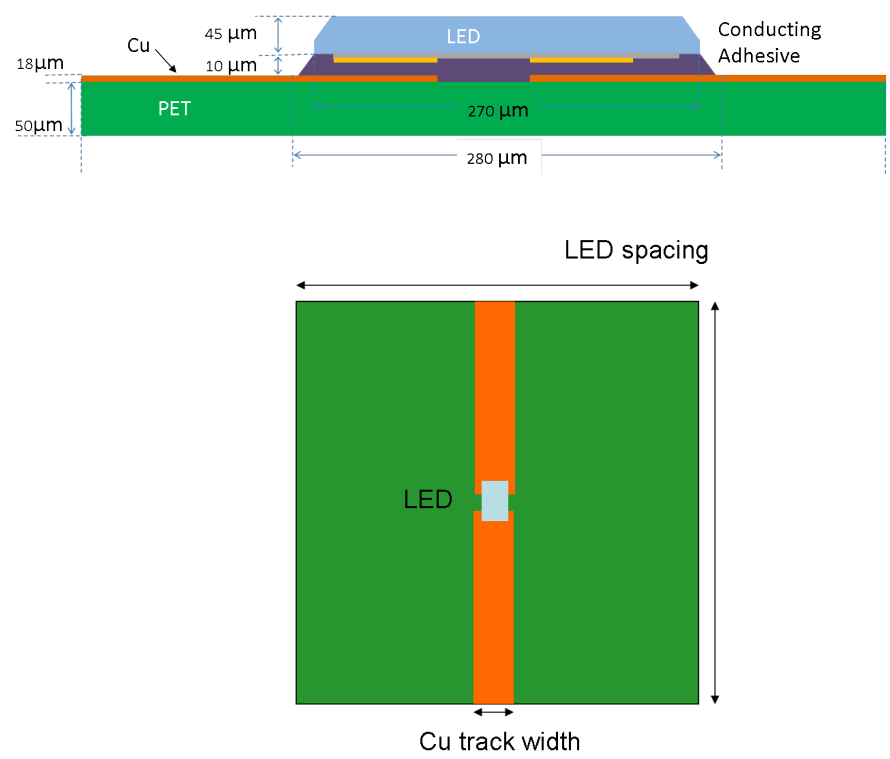

Figure 1: Model parameters for the surface mounted bare die LED.

The model was made using a commercial FE package (COMSOL 4.2a). The LED is modeled as a heat source. The heat generated by the LED is taken from the specifications of the supplier. It is assumed that heat generation is distributed uniformly over the InGaN volume. All simulations were performed at ambient temperature (default: $23{ }^{\circ} \mathrm{C}$ ) and in a 
stationary air environment (i.e. no forced air flow was considered, only natural convection). The stationary air environment can be considered a worst case scenario, since any kind of forced air flow will increase the convective heat transfer from the device. In stationary air, the surface will transfer heat to the surrounding air, inducing advection in the air. The heat flux is simulated using a heat transfer coefficient, $h$ between the surface and the surrounding air. The heat flux through the surface-air interface is approximated using the equation:

$$
-\vec{n}(-k \nabla T)=h\left(T_{a m b}-T_{\text {surf }}\right)
$$

Where $-\vec{n}(-k \nabla T)$ represents the direction and magnitude of the heat flux and $T_{a m b}$ and $T_{\text {surf }}$ are the ambient temperature and surface temperature respectively. The precise value of $h$, depends on the properties of the surrounding air, orientation of the surface with respect to gravity and on the size scale of the geometry [7]. In modelling simulations, COMSOL default values were used for air properties and a nominal value of $1 \mathrm{~m}$ was taken for the size scale of the geometry.

\section{Experimental}

Several SMT LEDs on PET foil samples were manufactured for thermal model validation purposes. Cree TR2227 blue light LED dies were mounted on $\mathrm{Cu}$ tracks on a heat stabilized PET foil/Cu laminate substrate (GTS laminates) with a DELO AC163 anisotropic conducting adhesive (ACA), using a dr. TRESKY T3200 semiautomatic bonder. The adhesive was applied by stencil printing. The LEDs were subsequently bonded at elevated temperature and pressure according to adhesive specification. To obtain information on the temperature distribution, thermal measurements were performed using and infrared thermal camera (FLIR Thermovision A40 IR). The camera was calibrated for emissivity of the PET by attaching a thermocouple to the PET foil next to the LED. Good heat conductivity of the connection was ensured by adding a drop of heat conductive paste (DOW corning 340 Heat Sink Compound). The LED was switched on and thermocouple and IR camera outputs were measured simultaneously. The thermocouple acts as a heat sink, therefore the thermocouple was removed after calibration of the camera to avoid influence on the temperature distribution measurements during LED operation. The thermal images of the LED on foil device were corrected for different emissivity of the materials by comparing the apparent temperature for each region at room temperature and adjusting the emissivity of the materials until the measured (apparent) temperature is equal to the room temperature.

Two different methods of interconnecting the bare die LED to the PET foil have been investigated: using an anisotropic conductive adhesive and using an isotropic conductive adhesive. As the anisotropic conductive adhesive, a DELO AC163 was used. As the isotropic conductive, a Henkel CE3104 WXL was used. The ACA adhesives were applied by stencil printing a $400 \times 400 \mu \mathrm{m}^{2}$ area around the bonding area of the $\mathrm{Cu}$-PET foil. The ICA conducts electricity in every direction. Therefore only two small dots of adhesive $(60 \mu \mathrm{m}$ diameter) were precision stencil printed on the substrate bonding area. On some of the ICA bonded samples a globtop adhesive was applied (Hysol 7400) which was UV cured at room temperature. The bonded samples were subjected to several reliability tests and evaluated for light output after testing:

1. Temperature/humidity test $(\mathrm{T} / \mathrm{RH}$, $\left.85^{\circ} \mathrm{C} / 85 \% \mathrm{RH}\right), 300 \mathrm{~h}$

2. Temperature shock test (TST, $-40^{\circ} \mathrm{C} / 125^{\circ} \mathrm{C}$, 30 min cycle time), 2 x300 cycles

3. Mechanical flexing test. 100 cycles.

The samples were flexed on cylinders with progressively decreasing bending radius (see [8] for details of the test). The LEDs were tested at a fixed point while strained around the cylinder.

\section{Modelling results}

The model was validated by comparing experimentally measured values of several different devices to the model predictions. The temperature distribution as well as the absolute measured temperature is compared. A typical modeled temperature distribution is found in Figure 2.

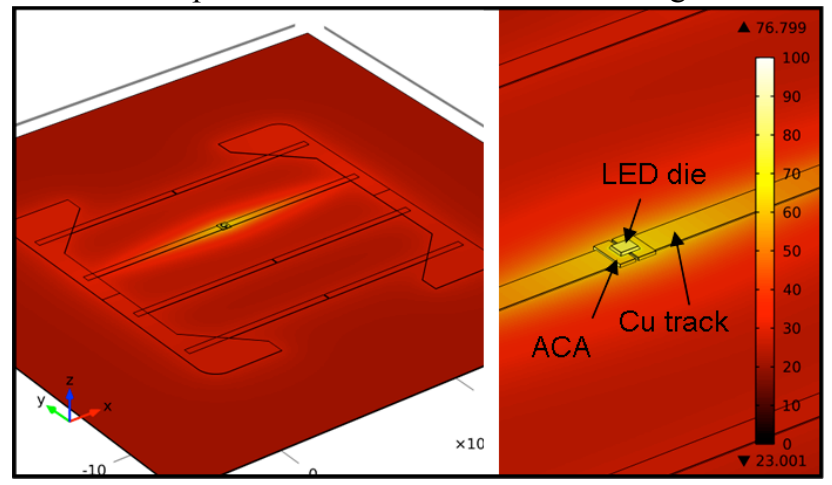

Figure 2: Typical simulation results for temperature distributions in the ACA bonded LED die at a heat output of $29.6 \mathrm{~mW}$ (left). The maximum temperature occurs in the LED (Die and SiC substrate) and the surrounding conductive adhesive (right).

In Figure 3, the test foil used for validation experiments is shown and the thermal camera images recorded at different heat output levels of the LED are shown in Figure 4.

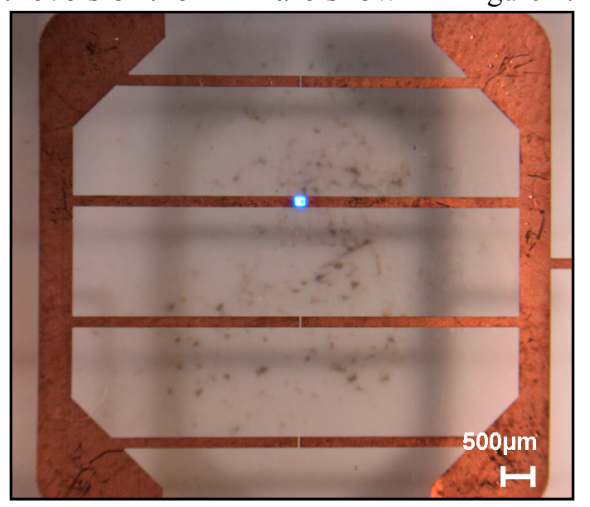

Figure 3: Test foil used for model validation experiments. The LED (blue) is operated at low forward voltage. 


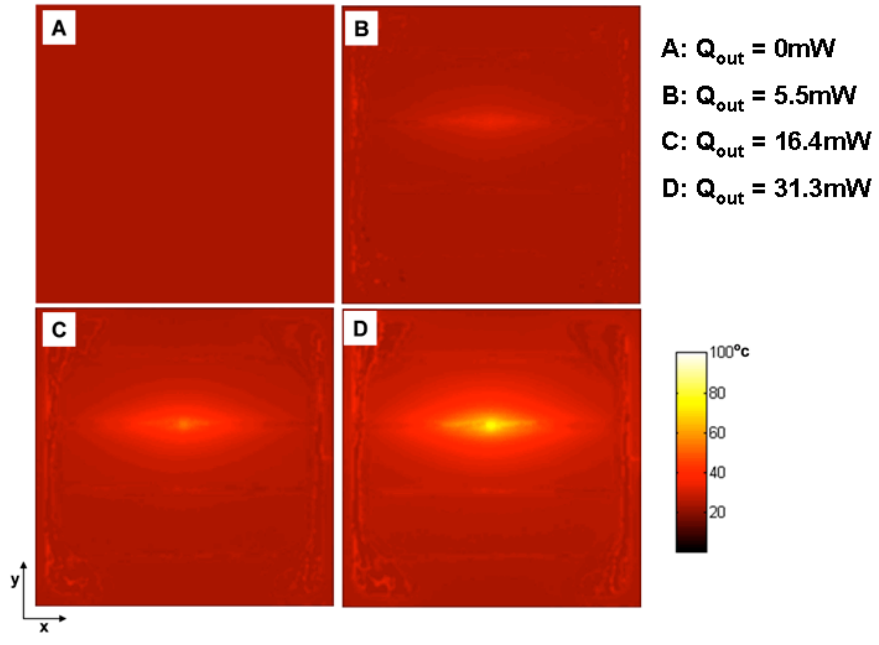

Figure 4: Thermal camera recorded temperature distributions at different heat power outputs $\left(Q_{\text {out }}\right)$.

The position of the LED is visible in Figure 4 as the peak temperature position. The increase in temperature is evidently the result of the higher heat output of the LED in pictures A to D. The copper tracks are efficient heat spreaders due to their high thermal conductivity (see also Figure 6). The low $\mathrm{Cu}$ fraction in the test design is a result of the test foil not being optimized for heat dissipation.

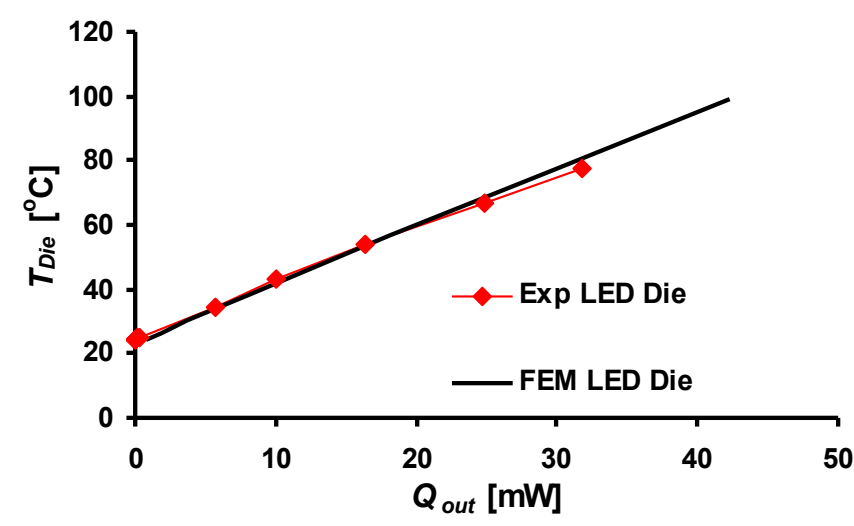

Figure 5: Maximum measured and simulated temperature in both LED configurations, the $\mathrm{Q}_{\text {out }}$ values of the LED were calculated by subtracting the radiative power output, specified in the datasheet, from the input power.

The peak temperatures are found in the LED die and adhesive. $\mathrm{Cu}$ tracks are efficient heat spreaders, while the PET materials show a sharp decay in temperature away from the LED die.

The model data fits the experimentally observed values well in the measured range for both peak values (Figure 5) and distributions (Figure 6). There are however some slight deviations. A slightly higher temperature was found in the PET layers and a lower temperature in the $\mathrm{Cu}$ layers than the model predictions. This is probably caused by a minor difference in thermal conductivity between the modeled PET system and the material used in the experiment, or minor differences in emissivity.

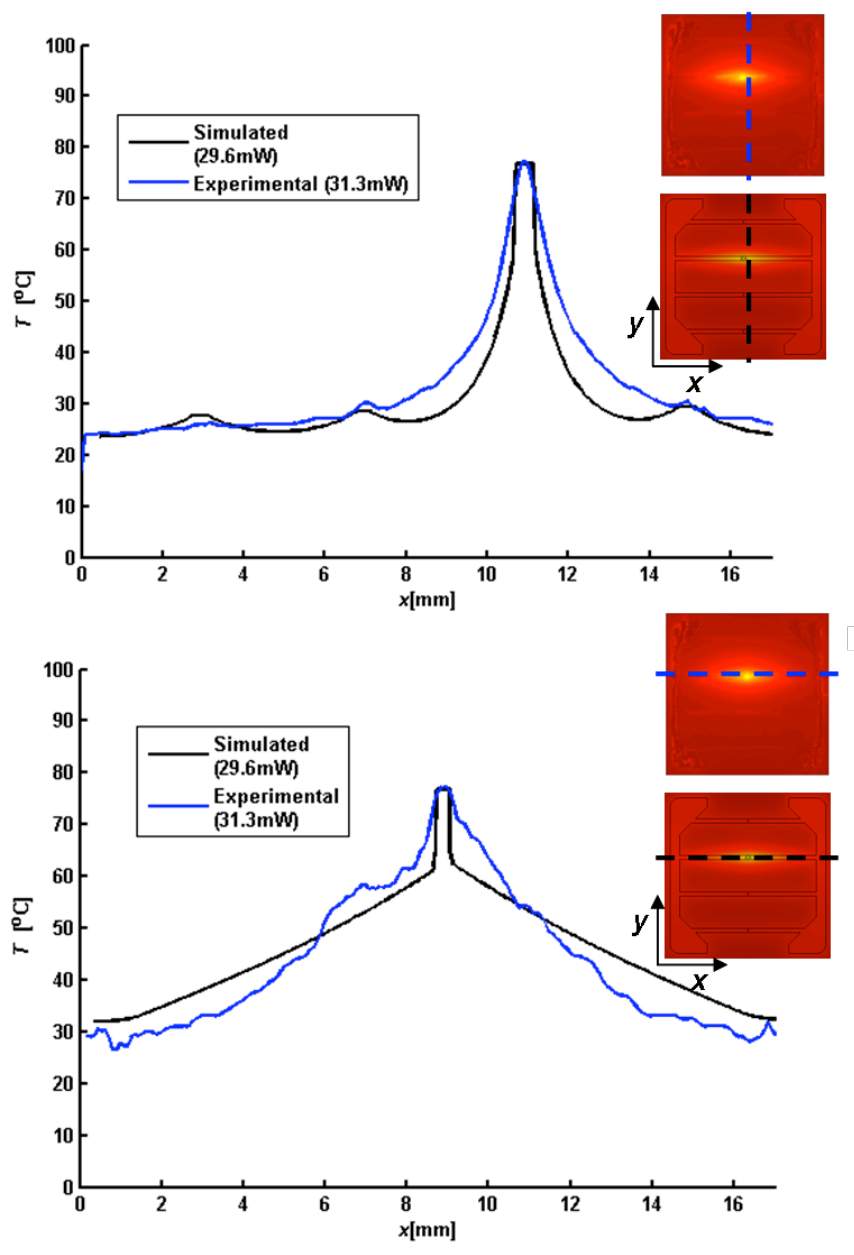

Figure 6: Maximum measured and simulated temperature in both LED configurations, the $\mathrm{Q}_{\text {out }}$ values of the LED were calculated by subtracting the radiative power output, specified in the datasheet, from the input power.

Furthermore, the infrared thermal imaging technique is more suited to material with a high emissivity coefficient. The $\mathrm{Cu}$ values have a higher uncertainty. For small $\mathrm{Cu}$ widths, such as the tracks to the LED position, the error is reduced due to the finite resolution of the camera. In the areas in the device where large parts of $\mathrm{Cu}$ are present, the recalculated values show more scatter. This is due the relatively large corrections to the measured values based on the emissivity of PET as well as the variations in $\mathrm{Cu}$ emissivity itself (roughness, oxidation stains, scratches). Variations also arise because of the unflatness of the foil, leading to changes in reflected radiation.

\section{Simulation study}

The following parameters are expected to be relevant for the heat distribution and dissipation in the device:

- Thermal conductivity $(k)$ of the conductive adhesive between LED and copper tracks. As the adhesive is an essential part of the thermal path from LED to the substrate, the conductivity of this component may have a large influence on the temperature distribution in the device.

- Width of the copper tracks. Default value is $1 \mathrm{~mm}$ width. Experiments have shown that the copper 
tracks are an effective heat sink, which suggests that wider copper parts would improve the heat dissipation.

- Emission coefficient $(\varepsilon)$ of copper. Especially for metals, the surface condition significantly affects the emissivity. For clean and polished surfaces, $\varepsilon$ can be as low as 0.001 . For oxidized or treated surfaces, $\varepsilon$ may be as high as 0.7 .

- Heat generation in the LED die. This value depends on the LED input voltage. The heat generation at default forward voltage is $42 \mathrm{~mW}$.

- $\quad$ LED spacing $(w)$. The spacing between LEDs in the array determines the area contributing to heat dissipation.

These parameters were evaluated in a 3 point full factorial DoE study. The parameter values are summarized in Table 1.

Table 1: Parameters values used in the simulation experiments.

\begin{tabular}{|c|c|c|c|}
\hline Parameter & Low & Default & High \\
\hline $\begin{array}{c}\text { Width of the Cu tracks } \\
{[\mathrm{mm}]}\end{array}$ & 0.2 & 1 & 3 \\
\hline \begin{tabular}{c} 
LED spacing, $w[\mathrm{~mm}]$ \\
\hline $\begin{array}{c}\text { Thermal Conductivity } \\
\text { Adhesive [W/m·K] }\end{array}$
\end{tabular} & 3 & 10 & 30 \\
\hline $\begin{array}{c}\text { Heat out }(\mathrm{LED} \text { power }) \\
{[\mathrm{mW}]}\end{array}$ & 1.72 & 42 & 66 \\
\hline Emissivity of Cu, $\varepsilon_{C u}[-]$ & 0.1 & 0.5 & 0.7 \\
\hline
\end{tabular}

The influence of each of the parameters on the temperature that is attained at different positions in the system can be seen in Figure 7. The maximum temperatures in the LED die are equal (within $0.1^{\circ} \mathrm{C}$ ) to the temperatures in the conducting adhesive. For the temperature in the conducting adhesive and LED die the most influential parameters are the heat output of the LED itself, the width of the $\mathrm{Cu}$ tracks and LED spacing. For a very low thermal conductivity of the conducting adhesive, the temperature in the LED die and conducting adhesive rapidly rises. The conductivity of the conducting adhesive is not of influence on the maximum temperature in the PET foil. The emission coefficient is of relatively little influence in this study. This is in part due to the relatively low area fraction of $\mathrm{Cu}$ that was used in the parameter study. When the $\mathrm{Cu}$ area fraction increases, the influence of emissivity is larger (see Figure 8).

Using the model the minimum LED spacing can be calculated. When constrained by the maximum use temperature of the PET, the minimum spacing of the optimized design is about $8 \mathrm{~mm}$. An $8 \mathrm{~mm}$ spacing between LED dies leads to a maximum density of 15000 LED dies per $\mathrm{m}^{2}$, resulting in a high light intensity system in foil.
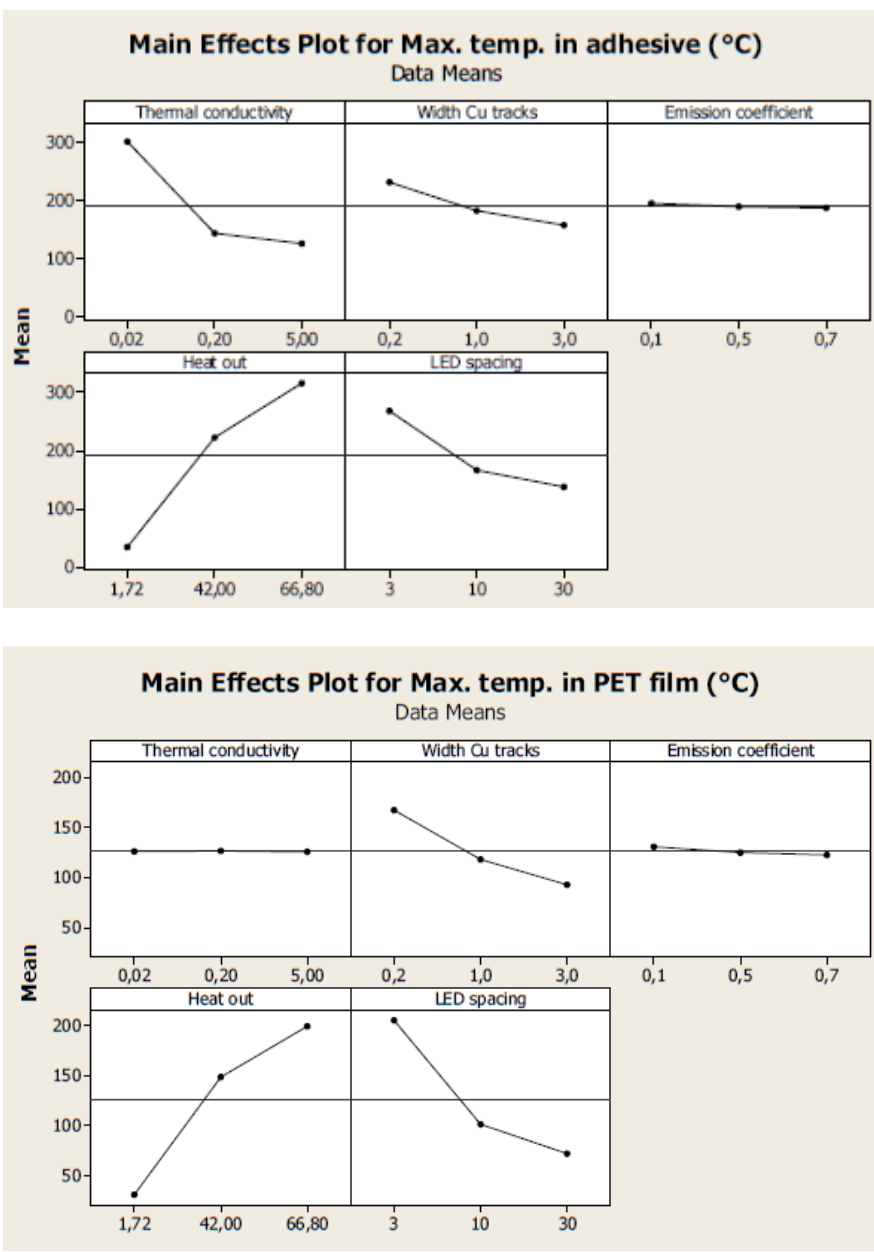

Figure 7: Main effects plots of the parameters varied on the maximum temperatures in the conducting adhesive (top) and PET foil (bottom) for the surface mounted LEDs. The y-axis values are in $\left[{ }^{\circ} \mathrm{C}\right]$.

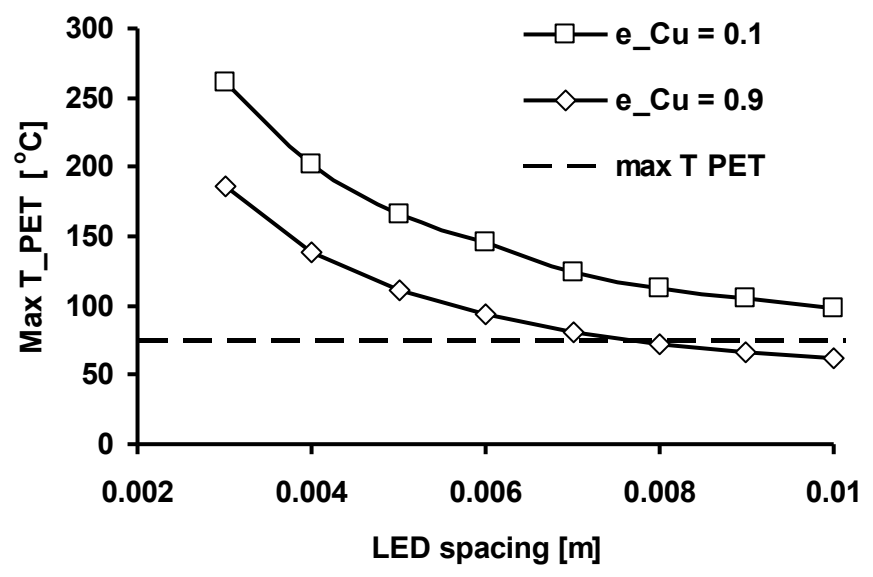

Figure 8: Maximum PET temperatures during operation at $42 \mathrm{~mW}$ heat output for a total $\mathrm{Cu}$ area fraction of close to 1 . The $\mathrm{Cu}$ emission coefficient, $\varepsilon_{C u}$, is set at the optimized value of 0.9 and the thermal conductivity of the adhesive is $0.2 \mathrm{~W} / \mathrm{mK}$. 


\section{Bonding experiments results}

Since the use of polyester substrates limits the use of bonding materials [5], different low temperature curing conducting adhesives were explored for the bonding of the bare die LEDs to the substrate (see Figure 9 and experimental section). The difference in thermal expansion between the PET foil, $\mathrm{Cu}$ tracks, adhesives and LED dies will cause thermal stresses during curing and other temperature fluctuations during operation. This could affect the stability of the bonds, which must be optimized towards handling these thermomechanical loads. Work towards achieving this is currently in progress.
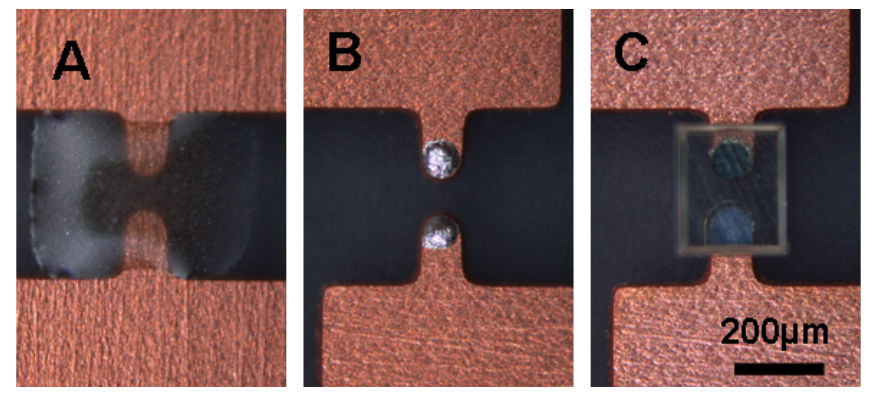

Figure 9: Stencil printed ACA adhesive (A) and ICA adhesive (B) and ICA bonded LED (C).

In Table 2, the number of samples that survived the respective tests out of the total number of samples tested is presented. In Figure 10 the number of failures as a function of bending radius of the flex test cylinder is presented. All results are after flexing for 100 cycles at the respective radius. Most failures occurred during the first 10 cycles at a certain radius.

Table 2: Summary of reliability of LED-Cu bonds with different bonding techniques. The number of LEDs producing light output at $\mathrm{V}_{\mathrm{f}}=3.2 \mathrm{~V}$ compared to the total number of LEDs is presented.

\begin{tabular}{|l|l|l|l|l|}
\hline $\begin{array}{l}\text { Bond } \\
\text { type }\end{array}$ & $\begin{array}{l}\text { Yield } \\
\text { after } \\
\text { curing }\end{array}$ & $\begin{array}{l}\text { T/RH } \\
(312 \mathrm{~h})\end{array}$ & $\begin{array}{l}\text { TST } \\
(312 \mathrm{~h})\end{array}$ & $\begin{array}{l}\text { Flex } \\
(\mathrm{r}=5 \mathrm{~mm})\end{array}$ \\
\hline ACA & $4 / 10$ & $\mathrm{~N} / \mathrm{A}$ & $\mathrm{N} / \mathrm{A}$ & $4 / 4$ \\
\hline $\begin{array}{l}\text { ICA w/o } \\
\text { Globtop }\end{array}$ & $42 / 43$ & $8 / 10$ & $19 / 22$ & $3 / 10$ \\
\hline $\begin{array}{l}\text { ICA with } \\
\text { Globtop }\end{array}$ & $21 / 24$ & $4 / 8$ & $2 / 8$ & $4 / 5$ \\
\hline
\end{tabular}

It can be seen in Table 2 that the ICA bonded samples have a better yield directly after bonding yield. Normally, the use of ACA requires a minimum bump height to establish a reliable contact. The gold-finished pads of these bare-die LEDs are only about $1 \mu \mathrm{m}$ thick. The cathode bond pad surface is level with the surface passivation coating of the die. Consequently, small deviations in tilting of the LED during bonding result in loss of contact. The size of the conductive particles is small, which leads to a very low tolerance to tilt. The tilt will reduce the area of the conductive path from the $\mathrm{Cu}$ track to the LED (see Figure 11) and can easily lead to premature failure.

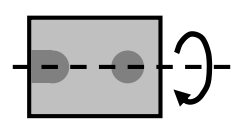

Short side

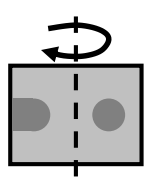

Long side

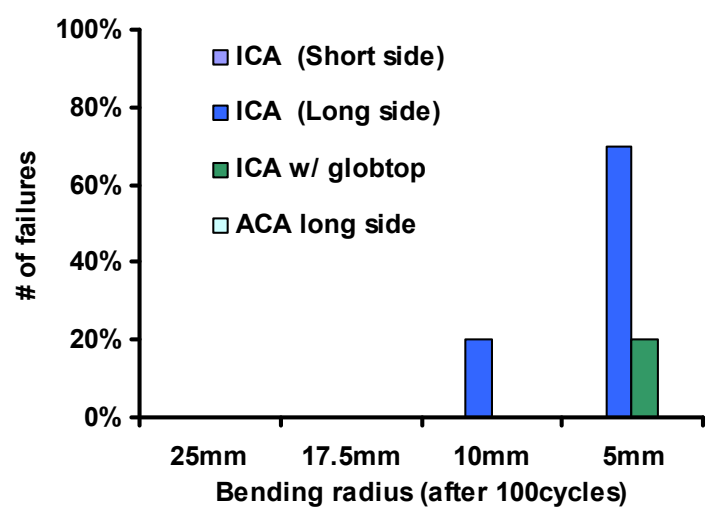

Figure 10: Number of failures as a function of bending radius for differently bonded LED dies. The ICA bonded samples are tested in both directions of the die.

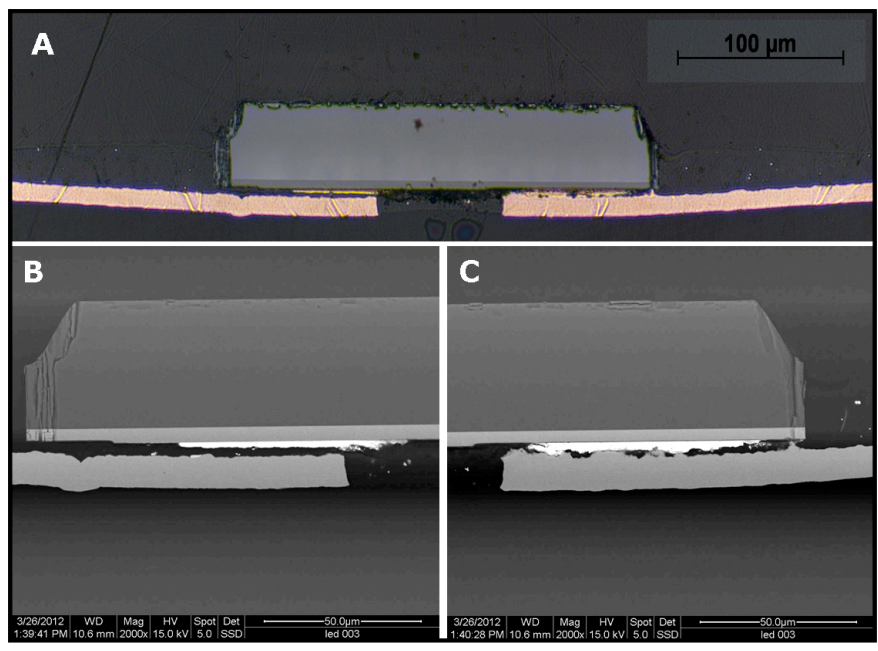

Figure 11: Cross section optical micrograph of ACA bonded LED die on PET-Cu foil (A). SEM micrographs of the left (B) and right $(\mathrm{C})$ bond pad areas show the importance of perfect alignment for electrical connection. In the left bond (B) a good connection was not established.

Bending stability measurements show a different trend. ACA bonded LEDs show extremely stable behavior in the flex test, whereas ICA bonded LEDs without globtop show failures during the flexing test at low bending radius. Adding adhesive volume evidently increases the stability of the bonded LEDs. For ACA bonded LEDs, if the LED has been placed right, robust contact is made. Contrarily ICA bonding of the LEDs is a high yield process, but the mechanical stability of the bond is relatively low compared to the ACA bonded LEDs. This is not surprising as the bond area is extremely small with the ICA bonding and high stresses can arise when bending [5]. Still, the thermal stability of the ICA 
bonded samples is relatively good (see Table 2). When a globtop adhesive is added, the mechanical stability of the bond increases (see Figure 10). However, thermal stability of the globtopped samples is low. This is possibly caused by the additional thermal strains exerted by the globtop on the bond by CTE differences, by strains on the bond caused by expansion of the globtop adhesive due to water uptake or by air entrapment during application of the globtop. The influence of the globtop adhesive on the reliability and the best choice of globtop material and application are still under investigation.

\section{Conclusions}

Deviations between experimentally observed maximum temperatures and simulated temperatures are less than $5^{\circ} \mathrm{C}$ in the power range investigated. Simulated temperature distributions over the $\mathrm{Cu}$ tracks slightly overestimate the temperature of the outside edges of the device and overestimate the reduction in temperature in the PET foil away from the $\mathrm{Cu}$ tracks. This expected to be related to the lead wires acting as extra heat sinks in the experiment, which were not present in the simulation and the result of slight variations in experimental material properties versus simulation values.

In the design of LED on foil systems, $\mathrm{Cu}$ area must be made as large as possible. The high thermal conductivity of the copper tracks efficiently spreads the heat over the foil area. Bare copper tracks contribute relatively little to the dissipation process, due to their low emissivity coefficient. This problem can be improved by coating the copper surfaces with a thin layer of high emissivity material to ensure adequate heat transfer to the environment.

The bonding of bare die LEDs can be achieved using anisotropic conducting adhesives as well as isotropic conducting adhesives. The ACA process is sensitive to failure during bonding, while the ICA process is more sensitive after bonding, especially during mechanical flexing at low bending radius, though room for optimization exists.

\section{Acknowledgments}

The authors would like to thank Freddie Furrer (TNO) for his help with the reliability experiments, Arthur Eijk (TNO) for the cross section imaging and Gert Van Heck (Holst Centre) for his assistance in electrical characterization.

\section{References}

1. J. van den Brand et al. "Systems-in-foil - Devices, fabrication processes and reliability issues" Microelectron. Reliability 48 (2008) pp.1123-1128.

2. Mukish et al., LED Cost and Technology Trends: How to enable massive adoption in general lighting, LED Forum Lyon - December 7th 2011

3. Kim, Y. W. et al., "Optimization of Flexible Substrate for Automotive LED Rear-Lamp" Proc. $11^{\text {th }}$ Electronics Packaging Technology Conference, Singapore, dec. 2009 pp. 926-929

4. Fjelstad, J., Flexible Circuit Technology, $4^{\text {th }}$ edition, BR Publishing Inc (Seaside, 2011) pp. 146-147

5. Van den Brand, J. et al., "Flipchip bonding of thin $\mathrm{Si}$ dies onto PET foils: possibilities and applications".
Proc. $18^{\text {th }}$ European Microelectronics and Packaging Conf. Brighton, UK, Sept. 2011. art. 6142415

6. Fjelstad, J., Flexible Circuit Technology, $4^{\text {th }}$ edition, BR Publishing Inc (Seaside, 2011) pp. 149

7. F.P. Incropera and D.P. DeWitt, Fundamentals of Heat and Mass Transfer, $5^{\text {th }}$ edition, John Wiley \& Sons (2002), Chapter 9.

8. Shridhar, A. et al, "Novel Interconnect Methodologies for Ultra-thin Chips on Foils" Proc $62^{\text {nd }}$ Electronic Components and Technology Conf, San Diego, CA, May. 2012, pp 238-245. 